Available online at Journal Website
https://ijma.journals.ekb.eg/
Main subject [Surgery [Cardiothoracic Surgery] ${ }^{*}$

Original article

\title{
Comparative study: Transseptal approach versus Transatrial approach in mitral valve replacement in redo patients
}

Mohamed Abdelazeem Hitawy [a]; Mohamed Shaffik Hassan [b]; Farag Ibrahim Abdelwahab[a]; Mohamed Elsayed Mousa[b]

Department of Cardiothoracic Surgery, Damietta Faculty of Medicine, Egypt $[\mathrm{a}]$.

Department of Cardiothoracic Surgery, Faculty of Medicine, Al-Azhar University, Egypt ${ }^{[b]}$

Corresponding author

Mohamed Abdelazeem Hitawy

Email: mhitawy@domazhermedicine.edu.eg

Received at: December 12, 2019; Revised at: May 23, 2020; Accepted at: May 27, 2020; Available online at: May 27, 2020

DOI: 10.21608/ijma.2020.20927.1052

\section{ABSTRACT}

Background: Previous cardiac operations may complicate mitral valve exposure, as adhesions and loss of mobility in the surrounding tissues may be present. In such cases, the conventional left atrial [LA] incision may not offer satisfactory visualization in the surgical site of the valve. Therefore, several alternative approaches have been proposed for satisfactory visualization of the mitral valve intraoperatively.

Aim of the work: To evaluate the outcome of the transseptal and transatrial approaches for mitral valve replacement in patients undergoing redo mitral valve surgery.

Patients and Methods: This is a prospective study that was conducted at Cardio-thoracic surgery department of Al-Azhar University hospital [Damietta] and other centers during the period from the January 2018 to May 2019. It included 30 patients undergoing redo mitral valve surgery; 15 of them had transseptal approach and 15 with transatrial approach.

Results: Age was comparable between studied groups. There were 6 males [40.0\%] in group I and 7 males [46.7\%] in group II. Smoking was reported in 8 [53.3\%] in group I and 7 [46.7\%] in group II. Hypertension and pulmonary disease were reported in 6 [40.0\%] versus 7 [46.7\%] and $2[13.3 \%]$ versus $3[20.0 \%]$ in groups I and II respectively. Diabetes mellitus was reported in 9 [60.0\%] in group I versus 4 [26.7\%] in group II. Finally, there was no significant difference between both approaches as regard to intraoperative or postoperative data.

Conclusion: Transatrial approach has been used in most of previous studies; the transseptal approach appears to be equally effective.

Keywords: Transseptal; Transatrial; Redo surgery; Mitral; Replacement.

This is an open access article under the Creative Commons license [CC BY] [https://creativecommons.org/licenses/by/2.0/]

Please cite this article as: Hitawy MA, Hassan MS, Abdelwahab FI, Mousa ME. Comparative study: Transseptal approach versus Transatrial approach in mitral valve replacement in redo patients. IJMA 2020; 2[3]: 619-624.

* Main subject and any subcategories have been classified according to the research topic. 


\section{INTRODUCTION}

Mitral valve diseases are among the most prevalent valvular heart diseases and necessitate surgical procedures for the repair or replacement of the mitral valve[1]. Good exposure is strictly required for mitral valve surgical repair, when the original valve is calcified or when a previous implanted synthetic valve prosthesis is removed. Mitral visualization may be inadequate due to left atrial small size and significant hypertrophy of the right ventricle[2]. Prior cardiac surgery may also complicate mitral valve exposure due to probable existence of adhesions and loss of mobility in the surrounding structures. In such situations, the conventional left atrial $[\mathrm{LA}]$ incision may not offer acceptable visualization of the valve at surgery. Therefore, several alternative approaches have been introduced to achieve adequate visualization of the mitral valve intraoperatively[3].

Since the introduction of mitral valve surgery, different techniques were tried to exposed the mitral valve, the two most commonly approaches are the left atriotomy, through incision in the interatrial groove, and trans-septal approach through incision in the interatrial septum after opening of the right atrium [4]

Conventional left atriotomy is the standard approach for most surgeons. However, the transseptal [TS] approach can confer better exposure to the mitral valve in cases where the left atrium is small, where there are adhesions caused by previous procedures, where there are concomitant operations requiring right atriotomy ${ }^{[5]}$. Nevertheless, for all the advantages that the TS approach offers, controversy regarding its outcome still exist. Indeed, whereas some studies have shown that the TS approach increases the risk of postoperative sinus nodal dysfunction and atrial fibrillation, others have implicated similar and comparable results for both LA and TS approaches[6].

\section{AIM OF THE WORK}

The current research had been designed to evaluate the outcome [safety and complications] of the transseptal and transatrial approaches for mitral valve replacement in patients undergoing redo mitral valve surgery.

\section{PATIENTS AND METHODS}

This is a prospective study that was conducted at Cardio-thoracic surgery department of Al-Azhar University hospital [Damietta] and other centers during the period from the $1^{\text {st }}$ of January 2018 to the last of May 2019. It included 30 patients undergoing redo mitral valve surgery; 15 of them had transseptal approach and 15 with transatrial approach.

Patients were included if they previously underwent mitral valve replacement due to stenosis or regurge and need redo surgery with or without other valve lesions, with preserved left ventricular function. On the other side, patient was excluded if he/she had ischemic heart disease, severe left ventricle systolic dysfunction $[<40 \%$ ], severe renal or hepatic dysfunction, and suffering from cerebrovascular accident with residual defect.

After selection, counseling, explaining the procedure to all participants, and obtaining a written consent to participate in the study; all participants were submitted to preoperative assessment in the form of detailed history, full clinical examination, laboratory work up, chest x ray, electrocardiography [ECG] for heart rhythm and presence of permanent pacemaker, transthoracic echocardiography and transesophageal echocardiography for assessment of ejection fraction, other valvular lesions, left atrial size and detection of left atrial thrombus.

The surgical techniques carried out as described by according to D'Agostino et al.[${ }^{[7]}$ and Botta et al. $[8]$

The intraoperative assessment included total operation time, total bypass time, cross clamp time, type of cardioplegia, femoral bypass, need for a temporary or permanent pacemaker after surgery, need for the inotropic support and other intraoperative complications.

The postoperative assessment included monitoring in intensive care unit [ICU], cardiac rhythm, need for transfusion and incidence of postoperative complications [myo-cardial infarction, cerebrovascular accident, renal failure, respiratory failure, sternal infection, pneumonia and early mortality], the need for inotropic support, hospital stay duration, and early postoperative laboratory investigations, ECG and echocardiography just before discharge from hospital. 
Statistical analysis of data: The collected data were documented, coded and analyzed by statistical package for social sciences [SPSS] version 19 [IBMBSPSS $®$ Inc., Chicago, USA], for windows. Qualitative data represented as frequency and percentage, while quantitative data, represented by mean, standard deviation [SD], minimum and maximum. For comparison, the independent samples, student's $[t]$ test, or Chi Square, Mann Whitney [U] tests were used. $p<0.05$ was set as the limit of statistical significance ${ }^{[9]}$.

Ethical considerations: The study protocol was approved by the local research and ethics committee of Damietta Faculty of Medicine, and an informed consent was obtained from each patient before participation in the study and after full explanation of the study protocol.

\section{RESULTS}

In the present study, age was nearly comparable between both groups [ $54.8 \pm 3.03$ years in group I \& $55.93 \pm 5.28$ years in group II]. There were 6 males [40.0\%] in group I and 7 males [46.7\%] in group II. Smoking was positive for 8 [53.3\%] in group I and 7 [46.7\%] in group II, while history of hypertension and pulmonary disease were reported for 6 [40.0\%] versus 7 [46.7\%] and 2 [13.3\%] versus 3 [20.0\%] in groups I and II respectively. Finally, diabetes mellitus [DM] was positive for 9 [60.0\%] in group I versus 4 [26.7\%] in group II. The New York Heart Association [NYHA] classification of angina revealed that, there were 3 [20.0\%] with no symptoms and no limitation in ordinary physical activity [class I] in group I versus 4 [26.7\%] in group II; 2 [13.3\%] with mild symptoms [mild shortness of breath and/or angina] and slight limitation during ordinary activity [class II] in group I versus 1 [6.7\%] in group II, no cases with marked limitation in activity due to symptoms, even during less-than-ordinary activity [class III] in group I, versus 1 [6.7\%] in group II; and 1 [6.7\%] with severe limitations [experiences symptoms even while at rest [class IV] in group I versus no cases in group II. Furthermore, dyspnea status pre-surgery revealed that, there were $2[13.3 \%]$ with no limitation of physical activity in group I versus 3 [20.0\%] in group II; 5 [33.3\%] with slight limitation of ordinary activity versus 4 [26.7\%] in group II; 6 [40.0\%] with marked limitation of ordinary physical activity in group I versus 6 [40.0\%] in group II; and 2 [13.3\%] with symptoms at rest or minimal activity in group I versus 2 cases [13.3\%] in group II [Table 1].

As regard preoperative heart rhythm, there were 9 [60.0\%] with sinus rhythm in group I versus 8 [53.3\%] in group II, 6 [40.0\%] with Atrial fibrillation/ flutter versus 6 [40.0\%], no cases with complete heart block/pacing versus 1 [6.7\%] and no cases in studied groups with ventricular fibrillation or ventricular tachycardia and others, respectively. The ejection fraction $[E F]$ grading revealed that, there were 12 [80.0\%] with Good [LVEF>50\%] in group I versus 11 [73.3\%] in group II, 2 [13.3\%] with fair [LVEF 30\%-50\%] versus 3 [20.0\%] in group II and 1 [6.7\%] with poor [LVEF $<30 \%$ ] in group I versus 1 $[6.7 \%]$, in group II. In addition, there were 6 cases [40.0\%] with redo-sternotomy in group I versus 7 [46.7\%] in group II, 6 [40.0\%] with femoral bypass versus $6[40.0 \%]$ and 3 [20.0\%] with thoracotomy incision in group I versus 2 [13.3\%] in group II with non-statistical significant difference [Table 2].

In the present study, the mean cumulative crossclamp time was $83.4 \pm 6.62$ minutes in group I versus $81.8 \pm 8.74$ minutes in group II and mean cross-clamp time [MV replace] was $73.13 \pm 6.08$ minutes in group I versus $72.8 \pm 6.79$ minutes in group II. The mean cumulative bypass time was $99.2 \pm 7.66$ in group I versus $96.4 \pm 10.08$ minutes in group II and mean MV replace was $93.9 \pm 5.17$ minutes in group I versus $92.8 \pm 6.35$ minutes in group II. The post-operative blood loss at 12 hours was $330.0 \pm 50.5 \mathrm{ml}$ in group I versus $300.0 \pm 70.1 \mathrm{ml}$ in group II. The intensive therapy unit [ITU] stay was $3.5 \pm 1.06$ days in group I versus $4.07 \pm 1.09$ days in group II. Finally, there were 1 [6.7\%] with reoperation for bleeding or tamponade in group I versus 1 [6.7\%] in group II, and 1 [6.7\%] with post-operative neurological dysfunction versus 1 [6.7\%] in group II, 1 [6.7\%] with hemofiltration [HF]/dialysis postoperatively in group I versus $2[13.3 \%]$ in group II, 2 [13.3\%] with systemic inflammatory response syndrome [SIRS] in group I versus 3 [20.0\%] in group II and 1 [6.7\%] requiring new pacemaker versus $0[0.0 \%]$ in group I versus group II respectively and 2 [13.3\%] with ITU readmission versus 1 [6.7\%] in groups I and II respectively [Table 3]. 
Hitawy MA, et al.

Table [1]: Demographic data of the studied cases.

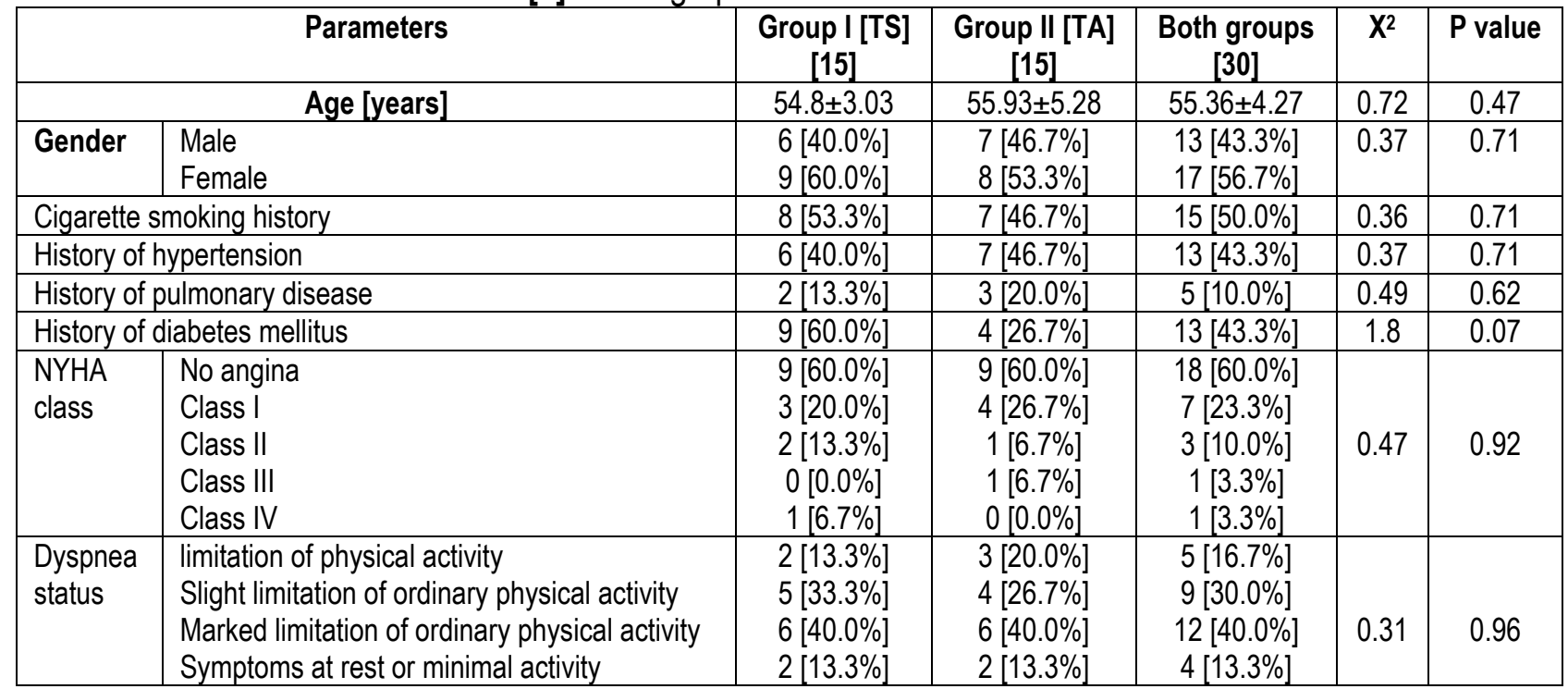

Table [2]: Comparison between the studied cases regarding preoperative heart rhythm

\begin{tabular}{|l|l|c|c|c|c|c|}
\hline & \multicolumn{1}{|c|}{ Parameters } & Group I & Group II & Both groups & $\mathbf{X}^{2}$ & P value \\
\hline Heart & Sinus rhythm & {$[15]$} & {$[15]$} & {$[30]$} & & \\
Rhythm & Atrial fibrillation/flutter & $9[60.0 \%]$ & $8[53.3 \%]$ & $17[56.7 \%]$ & & \\
& Complete heart block/pacing & $6[40.0 \%]$ & $6[40.0 \%]$ & $12[40.0 \%]$ & & \\
& Ventricular fibrillation or ventricular tachycardia & $0[0.0 \%]$ & $1[6.7 \%]$ & $1[3.3 \%]$ & \multirow{3}{*}{0.15} & 0.93 \\
& Other abnormal rhythm & $0[0.0 \%]$ & $0[0.0 \%]$ & $0[0.0 \%]$ & \\
\hline Ejection & Good [LVEF>50\%] & $0[0.0 \%]$ & $0[0.0 \%]$ & $0[0.0 \%]$ & & \\
Fraction & Fair [LVEF 30\%-50\%] & $12[80.0 \%]$ & $11[73.3 \%]$ & $23[76.7 \%]$ & & \\
& Poor [LVEF<30\%] & $2[13.3 \%]$ & $3[20.0 \%]$ & $5[16.7 \%]$ & 0.24 & 0.89 \\
\hline Surgical & Redo-sternotomy & $1[6.7 \%]$ & $1[6.7 \%]$ & $2[6.6 \%]$ & & \\
Technique & Femoral bypass & $6[40.0 \%]$ & $7[46.7 \%]$ & $13[43.3 \%]$ & \multirow{2}{*}{0.61} & \multirow{2}{*}{0.96} \\
& Thoracotomy incision & $6[40.0 \%]$ & $640.0 \%]$ & $12[40.0 \%]$ & 0.61 & \\
\hline
\end{tabular}

Table [3]: Comparison between studied cases regarding post-operative assessment

\begin{tabular}{|c|l|c|c|c|c|c|}
\hline & \multicolumn{1}{|c|}{ Parameters } & $\begin{array}{c}\text { Group I } \\
{[15]}\end{array}$ & $\begin{array}{c}\text { Group II } \\
{[15]}\end{array}$ & Both groups [30] & T test & P value \\
\hline Intraoperative & Cumulative cross-clamp time [min] & $83.4 \pm 6.62$ & $81.8 \pm 8.74$ & $82.6 \pm 7.66$ & 0.56 & 0.57 \\
\cline { 2 - 7 } Assessment & Cross-clamp time [MV replace] & $73.13 \pm 6.08$ & $72.8 \pm 6.79$ & $72.97 \pm 6.34$ & 0.14 & 0.89 \\
\cline { 2 - 7 } & Cumulative bypass time [min] & $99.2 \pm 7.66$ & $96.4 \pm 10.08$ & $97.8 \pm 8.9$ & 0.86 & 0.39 \\
\cline { 2 - 7 } & Bypass time [MV replace] & $93.9 \pm 5.17$ & $92.8 \pm 6.35$ & $93.36 \pm 5.7$ & 0.54 & 0.59 \\
\hline Postoperative & Blood loss at 12 hours [mL] & $330.0 \pm 50.5$ & $300.0 \pm 70.1$ & $312.0 \pm 63.57$ & 1.49 & 0.15 \\
\cline { 2 - 7 } Assessment & ICU stay in days & $3.5 \pm 1.06$ & $4.07 \pm 1.09$ & $3.8 \pm 1.09$ & 1.35 & 0.19 \\
\hline Postoperative & Reoperation for bleeding or tamponade & $1[6.7 \%]$ & $1[6.7 \%]$ & $2[6.7 \%]$ & ----- & ----- \\
\cline { 2 - 7 } Complications & Patients requiring new pacemaker & $1[6.7 \%]$ & $0[0.0 \%]$ & $1[6.7 \%]$ & 1.02 & 0.31 \\
\cline { 2 - 7 } & New post-op neurological dysfunction & $1[6.7 \%]$ & $1[6.7 \%]$ & $2[6.7 \%]$ & ----- & ---- \\
\cline { 2 - 7 } & New HF/dialysis postoperatively & $1[6.7 \%]$ & $2[13.3 \%]$ & $3[10.0 \%]$ & 0.61 & 0.54 \\
\cline { 2 - 7 } & SIRS & $2[13.3 \%]$ & $3[20.0 \%]$ & $5[16.7 \%]$ & 0.49 & 0.62 \\
\cline { 2 - 7 } & Patient status at discharge [mortality] & $1[6.7 \%]$ & $1[6.7 \%]$ & $2[6.7 \%]$ & ------ & ----- \\
\cline { 2 - 7 } & Sternal wound infection & $0[0.0 \%]$ & $0[0.0 \%]$ & $0[0.0 \%]$ & ---- & --- \\
\cline { 2 - 7 } & ITU readmission & $2[13.3 \%]$ & $1[6.7 \%]$ & $3[10.0 \%]$ & 0.61 & 0.54 \\
\hline
\end{tabular}

\section{DISUCSSION}

Redo cardiac surgery is a clinical challenge due to a high incidence of peri-operative complications and mortality [10]. The choice of a minimally invasive intervention to carry out mitral surgery is firmly related to surgeon's preference but the approach success is reliant on patient inclusion criteria, personal expertise capacities, availability of technological appliances, satisfactory training, and wise team-working of the staff, including anesthesiologists, perfusionists and nurses ${ }^{[11]}$. Minimally invasive surgical approach through right-sided minithoracotomy is a valid substitute to a repeated conventional median sternotomy ${ }^{[12] .}$

The incidence and prevalence of structural valve 
disease is increasing with advancing age and improved longevity. Surgical repair or replacement of valve is the standard of care for the treatment of significant valvular dysfunction, with bioprosthetic valves constituting more than $50 \%$ of approximately 300,000 valves implanted surgically worldwide. Although bioprosthetic heart valves allow freedom from lifelong anticoagulation, they are unfortunately associated with the risk of structural degeneration. The incidence of this structural valve deterioration requiring reintervention is $20 \%-30 \%$ at 10 years and approximately $50 \%$ at 15 years. Increasing life expectancy and shorter durability of tissue valves is likely to translate into increasing pool of patients with failing tissue valves requiring repeat intervention. At present, surgical replacement remains virtually the only available treatment for degenerated tissue valves. However, redo surgery for bioprosthetic valve failure carries a high mortality of around $3 \%$ $23 \%$. [14] In the present study, redo mitral valve more common at advanced age and in female than male and these results agreed with Gurvitch et al.[13] and Chandra et al.[14] who reported that advancing age, female sex, renal or pulmonary dysfunction, severity and urgency of disease, and number of previous redo surgeries are some of the factors associated with increased risk.

Guerrero et al. [ ${ }^{6}$ done their work on 494 patients and showed that the mean age was 76 years who underwent redo mitral valve and these age was more than age of our study due to large sample size of their study when compared with our study and $60.9 \%$ were females.

Failure of mitral valve prostheses in older patients who had multiple comorbidities is a high-risk clinical scenario with redo surgery[15].

Regarding ejection fraction, there were 12 [80.0\%] with Good [LVEF>50\%] in group I versus 11 [73.3\%] in group II, 2 [13.3\%] with fair [LVEF 30\%$50 \%$ ] versus 3 [20.0\%] and 1 [6.7\%] with poor [LVEF $<30 \%$ ] versus 1 [6.7\%], respectively. The trans-atrial approach may decrease apical function of left ventricle but it is transient. [16] In patients with already decreased ejection fraction of left ventricle or with functional regurge of mitral valve, it may be a less than optimal approach. It may also be technically difficult if there is a pre-existing prosthetic heart valve in the aortic position [17], whereas the TS approach may be less challenging. However, limited data are available [18].

In conclusion, trans-septal approach seems to be similarly effective and safe as trans-atrial approach. However, long-term researches are required to establish the proportional efficacy of one approach over the other.

Limitations of the study: the main limitations of the present work is the small number of included subjects and the inability to randomize our patients.

\section{Financial and Non-Financial Relationships and Activities of Interest}

\section{None}

\section{REFERENCES}

1. lung $B$, Vahanian $A$. Epidemiology of valvular heart disease in the adult. Nat Rev Cardiol. 2011; 8:162-172. [DOI: 10.1038/nrcardio.2010.202].

2. Mujtaba SS, Clark SC. Extended trans-septal versus left atrial approach in mitral valve surgery: 1017 patients' experience. Heart Asia. 2018; 10[2]:e011008.. [DOI: 10.1136/heartasia-2018-011008].

3. Masiello $P$, Triumbari F, Leone R, Itri F, Del Negro G, Di Benedetto G. Extended vertical transseptal approach versus conventional left atriotomy for mitral valve surgery. J Heart Valve Dis.1999; 8[4]:440-4. [PMID: 10461245].

4. Aydin E, Arslan A, Ozkokeli M. Comparison of superior septal approach with left atriotomy in mitral valve surgery. Rev Bras Cir Cardiovasc. 2014; 29[3]:367-73. [DOI:10. 5935/ 1678-9741.20140045].

5. Salerno TA, Suarez MR, Panos AL, Macedo Fl, Alba J, Brown M, Ricci M. Efficacy, feasibility, and pitfalls of transseptal approach in beating-heart mitral valve surgery. J Card Surg. 2009; 495:24-498. [DOI:10.1111/ j.1540-8191.2009. 00860.x].

6. Guerrero M, Wang Dee Dee D, Vemulapalli S, Xiang K, Salinger M. Clinical outcomes of transcatheter mitral valve replacement for degenerated mitral bioprostheses [mitral valve-in-valve] and surgical rings [mitral valve-inring] in the United States: Data from the STS/ACC/TVT registry. Circulation 2017; 136[Suppl 1]: Abstract 23079

7. D'Agostino RS, Jacobs JP, Badhwar V, Fernandez FG, Paone G, Wormuth DW, Shahian DM. The Society of Thoracic Surgeons: Adult Cardiac Surgery Database: 2018 Update on Outcomes and Quality. Ann. Thorac. Surg. 2018; 105[1]:15-23. [DOI: 10.1016/ j.athoracsur. 2017.10.035].

8. Botta L, Cannata A, Bruschi G, Fratto P, Taglieri C, Russo CF, Martinelli L. Minimally invasive approach for redo mitral valve surgery. J Thorac Dis. 2013; 5[6]:686693. [DOI: 10.3978/j.issn. 2072-1439.2013.10.12]. 
9. Ali Z, Bhaskar SB. Basic statistical tools in research and data analysis. Indian J Anaesth. 2016, 60[9]:662-669. [DOI: 10.4103/0019-5049.190623].

10. Botta L, Cannata A, Fratto P, Bruschi G, Trunfio S, Maneggia C, Martinelli L. The role of the minimally invasive beating heart technique in reoperative valve surgery. J Card Surg. 2012; 27:24-8. [DOI:10.1111/ j.1540-8191.2011. 01358.x].

11. Modi P, Hassan A, Chitwood WR. Minimally invasive mitral valve surgery: a systematic review and metaanalysis. Eur J Cardiothorac Surg. 2008; 34:943-52. [DOI: 10.1016/j.ejcts.2008.07.057].

12. Botta L, Cannata A, Bruschi G, Fratto P, Martinelli L. Beating heart mitral valve surgery: innovation or back to the past? J Card Surg. 2010; 25: 318-406. [DOI:10.1111/j.1540-8191.2010.00998_1.x].

13. Gurvitch R, Cheung A, Ye J, Wood DA, Willson AB, Toggweiler S, Binder R, Webb JG. Transcatheter valvein-valve implantation for failed surgical bioprosthetic valves. J Am Coll Cardiol. 2011; 1:2196-209. [DOI: 10.1016/j.jacc.2011.09.009].

14. Chandra P, Goel R, Chouhan NS. Transcatheter mitral valve replacement for failed mitral bioprosthesis: The new frontier. Indian Heart J Interv. 2018; 1:63-70. [DOI: 10. 4103/IHJI.IHJI_34_18].
15. Vohra HA, Whistance RN, Roubelakis A, Burton A, Barlow CW, Tsang GM, Livesey SA, Ohri SK. Outcome after redo-mitral valve replacement in adult patients: a 10-year single-centre experience. Interact Cardiovasc Thorac Surg. 2012; 14:575-579. [DOI:10.1093/ icvts/ ivs005].

16. Barbash IM, Dvir D, Ben-Dor I, Corso PJ, Goldstein SA, Wang Z, et al. Impact of transapical aortic valve replacement on apical wall motion. J Am Soc Echocardiogr.2013; 26:255-260. [DOI: 10.1016/j. echo. 2012.11.003]

17. Wilbring M, Alexiou K, Tugtekin SM, Arzt S, Ibrahim K, Matschke K, Kappert U. Pushing the limits - further evolutions of transcatheter valve procedures in the mitral position, including valve-in-valve, valve-in-ring, and valve-in native- ring. J Thorac Cardiovasc Surg. 2014; 147:210-219. [DOI: 10.1016/j.jtcvs.2013.09.021].

18. Dvir D. Transseptal instead of transapical valve implantation: making mitral great again? JACC Cardiovasc Interv. 2016; 9:1175-1177. [DOI: 10.1016/j.jcin.2016.04.006]. 